${ }^{1}$ Universidade de São Paulo (USP)

Departamento de Antropologia, Brasil

hfrugoli@uol.com.br

Heitor Frúgoli Jr.'

\title{
A CIDADE SOB ENFOQUE ANTROPOLÓGICO: AS OBRAS DE RUTH FINNEGAN SOBRE MILTON KEYNES*
}

Este artigo adveio de indagações decorrentes das últimas experiências de pesquisa - nos contrapontos entre São Paulo e Lisboa (Frúgoli Jr., 2013a; 2013b), cujos desdobramentos levaram à busca de um aprofundamento sobretudo teórico. Diferente de outros momentos, em vez de formular um novo trabalho de campo, busquei ler mais a fundo determinadas obras de antropólogos(as) que remetem basicamente à cidade, embora não se situem explicitamente no campo da antropologia urbana ${ }^{\mathrm{I}}$ - como dois livros de Ruth Finnegan: The hidden musicians: music making in an English town (2007 [1989]) e Tales of the city: a study of narrative and urban life (2004 [1998]).

O contato com tais escritos e, posteriormente, com a própria autora, ${ }^{2}$ levaram-me a visitar, por uma combinação de fatores e apenas por um dia, numa espécie de pré-campo absolutamente preliminar, a cidade de Milton Keynes, no sudeste inglês, a 7okm de Londres, com uma população estimada em 255,7 mil habitantes, ${ }^{3}$ foco das duas obras citadas.

Trata-se, assim, de um texto experimental que circunscreve uma somatória de questionamentos, provisórios e inscritos num work in progress, cuja elaboração busca sistematizar o caminho já percorrido, em diálogo com o espírito da seção de "registros de pesquisa" desta revista, com a intenção de contribuir para a ampliação do conhecimento antropológico sobre o contexto citadino. 


\section{DESAFIOS INICIAIS}

As motivações iniciais da investigação residem, sinteticamente, em descobertas decorrentes de uma pesquisa etnográfica em Lisboa, centrada no contexto de um bairro (Frúgoli Jr., 20I3a; 20I4), na qual enfrentei uma série de desafios ligados à abordagem de algo que, embora aparentemente próximo (pela partilha da língua portuguesa ou por certo conhecimento prévio do contexto português ou "lusófono"), revelou-se estranho em muitos planos. Dependendo da situação, havia dificuldade de entender palavras ou expressões, ou de compreender o significado mais profundo de comentários de alguns interlocutores, ou mesmo de me fazer entender, além de uma ilusão de familiaridade que era constantemente checada ou questionada por vários deles.

Se, de um modo geral, a construção da objetividade nas pesquisas em contextos urbanos passa por modalidades de enfrentamento das complexas relações entre familiaridade e estranhamento (Velho, I978; DaMatta, I978; Cavalcanti, 2003), pode-se também reconhecer que tal prática - sobretudo a de estranhar o familiar ou conhecido - se deve ao fato de que, na antropologia urbana brasileira, é muito recorrente que os antropólogos pesquisem dimensões socioculturais das próprias cidades em que residem. ${ }^{4}$

Ao contrário (de um modo geral) das pesquisas em São Paulo, em Lisboa foi preciso ir além da prática predominante da transformação subjetiva do (supostamente) familiar em estranho, para lidar com várias dimensões efetivamente estranhas. Configurou-se então um interesse particular pela trajetória de antropólogos(as) que tiveram experiências etnográficas marcadas por alteridades muito diversas, quando cotejadas entre si. ${ }^{5}$

Uma experiência brasileira pioneira, neste sentido, talvez tenha sido a de Gilberto Velho, ao observar uma comunidade de origem portuguesa (com predominância açoriana) em Cambridge, Estados Unidos, em I97I, entre seu mestrado e doutorado, feitos no Brasil. ${ }^{6}$ Vários antropólogos brasileiros (na maioria, antropólogas) já enfrentaram posteriormente este desafio, embora um balanço, vinte anos atrás (Velho, I995: 2), enfatizasse certa continuidade entre os desafios das pesquisas no território brasileiro (dada sua significativa heterogeneidade cultural) e no estrangeiro.?

O caminho aqui escolhido - mesmo com o reconhecimento das continuidades em investigações realizadas em contextos etnográficos distintos (quanto aos graus de alteridade ${ }^{8}$ ) pelo mesmo pesquisador - é atentar ao que também haja de descontínuo ou impactante em tais experiências, e que dessa forma permita uma ampliação do conhecimento antropológico.

Isto nos leva a uma inflexão na argumentação, abrindo-se um outro campo de reflexão, relativo a antropólogos reconhecidos cuja trajetória se pauta, grosso modo, por experiências etnográficas em contextos, digamos, não ocidentais, cujas abordagens posteriores se pautaram pela busca de uma com- 
preensão aprofundada da própria sociedade ou cultura (em certo detrimento de novas práticas etnográficas), como nos casos de Louis Dumont (I992 [I966] e I993) - cujo trabalho partiu do sistema holístico hierárquico de castas indiano para a abordagem da sociedade moderna ideologicamente individualista e igualitária -, de Roberto DaMatta (I979) - que veio da análise etnológica de sociedades tribais do Brasil central ao enfoque totalizante sobre a sociedade nacional - ou de Marc Augé (I994 [I992]) - que passou do estudo dos lugares assentados em sociedades tracionais africanas aos não lugares de circulação e consumo que pautariam as sociedades (sobre)modernas.

Em busca de uma síntese da argumentação até aqui delineada, a intenção básica no presente artigo é a de empreender uma investigação sistemática de duas obras de uma antropóloga cujos enfoques denotam certa variação em termos de alteridade etnográfica, nas quais a atenção sobre a cidade e suas dinâmicas socioculturais é relevante e alvo peculiar de investigação. É o que nos leva, basicamente, ao enfoque dos dois livros já citados da antropóloga britânica Ruth Finnegan.

\section{AS OBRAS DE RUTH FINNEGAN SOBRE O CONTEXTO URBANO}

Nascida em I933 na Irlanda do Norte, Finnegan foi aluna de graduação e depois orientanda de mestrado de Evans-Pritchard em Oxford, além de ter tido Godfrey Lienhardt como um dos seus tutores. Desenvolveu diversas pesquisas et nográficas na África - Serra Leoa, Rodésia do Sul e Nigéria - ao longo dos anos I960, voltadas a temas como histórias, literatura oral, alfabetização e poética (Finnegan, I967, I970, I988), seguidas, a partir de meados da década seguinte, pelo interesse em música urbana (fijiana, indiana e europeia) e performance, durante sua estada em Fiji entre I975 e I978 (Finnegan, 201 I). 9

Em I969, ela tornou-se docente da Open University (no ano de sua fundação), em Milton Keynes, onde lecionou na cadeira de Sociologia, até sua aposentadoria, como professora emérita. ${ }^{\text {to }}$ As experiências na África e na Oceania, bem como a vida cotidiana em Milton Keynes, incluindo sua participação num coro amador local, permitiram-lhe aos poucos compreender a importância de tais práticas musicais (amadoras, ou situadas num continuum entre o amador e o profissional) na vida urbana, em sua dimensão mais ampla quanto às redes de sociabilidade, levando-a ao estudo, desafiante e com o uso de diversas fontes, que culminou na escrita de The hidden musicians, em que a autora aprendeu "tanto sobre pessoas reais quanto entre histórias e narrações de histórias de Limba": ${ }^{\text {II }}$

Tomando o touro pelos chifres, decidi empreender um estudo etnográfico da música e das atividades musicais em minha própria cidade de Milton Keynes [...]. Minha intenção era de me aproximar dela como se fosse um cultura estranha [...] o método suscitava problemas, uma vez que os modos "tradicionais" de 
580

\begin{abstract}
observação participante adequados para uma comunidade em pequena escala precisam ser claramente ampliados e adaptados ao contexto urbano [...] embora estes métodos tradicionais realmente precisassem ser suplementados por outros (especialmente entrevistas e análise de imprensa), a observação face a face e a experiência direta continuaram a constituir o coração do estudo. (Finnegan, 2002, s/p, tradução minha)
\end{abstract}

Tal livro foi reconhecido por Roger Sanjek como uma "aplicação impressionante" dos pontos de vista de Ulf Hannerz (I980) sobre a vida urbana:

participantes de grupos musicais movimentam-se para locais de prática e performance; poucos grupos se baseiam em relações de vizinhança, e apenas em bandas de metais (brass bands) o parentesco conecta alguns membros; a maioria dos músicos não interage em situações não musicais, mas em vez disto, contam com diferentes conjuntos de consociados; nenhum dos grupos dura para sempre, e as pessoas movem-se para dentro e para fora enquanto esses existem; tal como os membros de muitas congregações, associações, organizações políticas e grupos de lazer urbanos, os músicos amadores estão ligados por práticas e não por relacionamentos duradouros e múltiplos; cada um segue seu próprio caminho urbano (urban pathway), movendo-se através de situações e domínios que variam em intimidade, continuidade, previsibilidade e elaboração simbólica. (Sanjek, 2002 [1996]: 557, tradução minha) ${ }^{12}$

É esta dimensão de uma antropologia da cidade presente em sua obra que se pretende aprofundar aqui, ainda que Finnegan seja mais conhecida, inclusive no contexto brasileiro, ${ }^{13}$ por suas contribuições à antropologia da música ou das práticas musicais, que a autora ressalta não se tratar de uma dimensão supostamente marginal da vida humana. ${ }^{14}$

A leitura de The hidden musicians (2007 [1989]) revela assim uma abrangência de fôlego sobre os "mundos musicais" 15 nitidamente existentes em Milton Keynes na primeira metade da década de i980: orquestras, pequenas orquestras independentes e corais de música clássica, bandas de metais, grupos de dança e bandas de música folk, sociedades e grupos amadores de ópera e teatro musical, bandas de jazz (várias delas com atuação em pubs e clubes), grupos de música country e western e dezenas de bandas de rock e pop, cujo olhar atento às simultaneidades revela âmbitos significativamente entrelaçados ou sobrepostos. ${ }^{16}$

Os contrastes e comparações (título da parte III) entre tais esferas desaguam no conceito de "mundos plurais" (título do capítulo I4, que integra essa parte), cada qual com suas convenções quanto à organização da aprendizagem, performance e criação do respectivo gênero musical (Finnegan, 2007: I80), todos eles igualmente autênticos (Finnegan, 2007: I8I) - o que leva à necessidade de se evitar hierarquias, por exemplo, entre práticas de música erudita e de rock/pop - embora não totalmente autônomos (Finnegan, 2007: I8I), com permeabilidades variáveis (Finnegan, 2007: I8I-I82) e articulações a esferas mais amplas, quanto a instituições e padrões referenciais (Finnegan, 
2007: I80-I83). Em síntese, se o termo "mundo" remete a ideias de coerência, concretude, estabilidade, abrangência e autonomia, é preciso ressaltar a pluralidade dos mesmos, cujas práticas musicais constituem uma espécie de sistema oculto (hidden system), ao investirem tais mundos de um caráter relativo, inconstante e situacional, dependentes tanto da ação individual e criação quanto das convenções externamente estabelecidas (Finnegan, 2007: I 90). Isto ajuda a entender porque "para muitos - ainda que não para todos - em Milton Keynes, as atividades musicais jogavam um papel muito significativo em sua implicação na sociedade circundante, na sociabilidade e na fixação de rotas temporais, espaciais e de ação, através das quais encontravam a realidade na cidade em que viviam, e, reciprocamente, ajudavam assim a conformá-la" (Finnegan, 2002, s/p, tradução minha).

Em certas passagens, a autora ressalta a "variedade de agrupamentos" (variety of groupings, Finnegan, 2007: 303), o que talvez traduza melhor a dinâmica dos fenômenos cambiantes estudados do que a menção a grupos, ${ }^{17}$ sendo por vezes mais apropriado pensar em redes, ainda que o principal seja ressaltar que se tratam de práticas, melhor capturadas e sumarizadas pela ideia de caminhos (pathways) por tais mundos, que embora possam conter eventuais marcações de classe, gênero ou idade, seriam assinalados sobretudo pela mistura de pessoas envolvidas em cada um deles, que predomina na música local (Finnegan, 2007: 312). Isso permite à autora afirmar que “

[...] a multiplicidade de caminhos corresponde à heterogeneidade sempre vista como uma característica da vida urbana, sendo a sobreposição de muitos caminhos relativamente distintos o reflexo de vidas multifacetadas, situacionais e em constante mudança que as pessoas levam em cidades hoje em dia. Mas eles acarretam, também, um senso de pertencimento e realidade, de movimentos não por ambientes estranhos, mas através de caminhos conhecidos no tempo e no espaço, em continuidade familiar e de ação habitual. (Finnegan, 2007: 324, tradução minha)

Passemos então ao próximo livro - Tales of the city (2004 [I998]) -, em que a estratégia etnográfica anterior dá lugar ao registro de relatos, com ênfase na reconstituição de trajetórias de vida de moradores de Milton Keynes (que não se relacionam necessariamente entre si), entendidas, em última instância, como contos, isto é, narrativas ou histórias dotadas de partes constitutivas - construções temporais sequenciais, explicações dotadas de coerência, com certo grau de generalidade, inscritas em determinadas convenções (Finnegan, 2004: I-I3). Um dado inovador, em certo diálogo com a perspectiva pós-moderna em antropologia, foi igualmente tomar a teoria urbana, em especial a sociologia urbana, como um conjunto de narrativas dotadas da mesma lógica interna, o que permite a Finnegan tematizar criticamente termos abstratos recorrentes como modernização, comunidade, progresso, exploração ou alienação, bem como os personagens que os dramatizam - consumidor, trabalhador, membro da elite, homem urbano, tipo metropolitano etc. (Finnegan, 2004: I4-23). 
Tal estratégia analítica permite uma análise mais aprofundada das particularidades urbanísticas de Milton Keynes, aspectos mais aludidos do que propriamente enfrentados no livro anterior, à luz de narrativas dos seus planejadores - personificados na Milton Keynes Development Corporation, "heroína gloriosa" desse conto (Finnegan, 2004: 34) - ligadas ao fato de se tratar de uma cidade planejada, ${ }^{18}$ cujo ponto de partida foi março de I967, quando da fundação da corporação, com vistas à criação do seu plano diretor (master plan), orientado por seis metas inter-relacionadas (retomadas posteriormente para balanços quanto à concretização): oportunidade e liberdade de escolha; movimentos e acessos facilitados, boas comunicações; balanço e variedade; uma cidade atrativa; consciência pública e participação; uso de recursos eficiente e imaginativo (Finnegan, 2004: 27-29). Tal narrativa evocaria conceitos como comunidade, cidade, cidadãos e ambiente, e culminaria - ao contrário das visões sombrias e pessimistas das miradas acadêmicas - numa espécie de concretização utópica ligada à vontade humana, à capacidade de forjar lugares e vidas, ao crescimento e amadurecimento de uma cidade em analogia a forças naturais, enfim, de um destino grandioso, forjado ao longo do tempo (Finnegan, 2004: 36), cuja inspiração viria, em boa parte, da concepção de cidades-jardim (garden cities) formuladas por Ebenezer Howard (I996 [I902]) (Finnegan, 2004: 36-4I), cuja ressonância no imaginário urbano inglês não será aqui aprofundada. ${ }^{19}$

Ainda no rol de narrativas que antecederam a pesquisa mais detida de Finnegan com os próprios residentes, consta um conjunto de histórias que se referem crítica e mesmo jocosamente à cidade de Milton Keynes, em boa parte veiculada pela imprensa, ${ }^{20}$ quanto à ausência de vida urbana, tradição, memórias, enfim, algo sem alma e deserto, povoado por residentes sem raízes (Finnegan, 2004: 4I), sem falar do descrédito quanto à artificialidade do planejamento urbano, que resultaria apenas numa ação de destruição do mundo rural e das tradições ali existentes (Finnegan, 2004: 42-44). Tal perspectiva ganhou uma forma mais depreciativa quando seis esculturas de vacas em concreto, feitas pela artista em residência Liz Leyh, foram doadas à cidade em 1978 e expostas a partir de então num parque, ensejando praticamente uma sinonímia entre Milton Keynes e as concrete cows, o que não deixa de reforçar, segundo Finnegan, uma vertente clássica de crítica à cidade moderna enquanto mero produto de uma burocracia artificial e impiedosa (Finnegan, 2004: 44-47). Isto suscitou, por sua vez, um conto contrastante (contrasting tale, Finnegan, 2004: 47) veiculado através de livros, panfletos, propagandas e afirmações verbais locais, que buscaram realçar a longa história das pequenas cidades e aldeias ao redor, com as quais os moradores e a própria cidade teriam se relacionado harmoniosamente (o que combinaria com a existência da vegetação como um fator da procura do local para moradia), reafirmando-se no caso a existência de um background de memórias, diversidade e tradições culturais. 
O estudo propriamente dito sobre os contos pessoais dos residentes de Milton Keynes concentrou-se na área de Fishermead, que em I 994 totalizava 4 mil habitantes, distribuídos em aproximadamente I,5 mil casas (Finnegan, 2004: I3I-I34), num momento em que a população total era por volta de I50 mil pessoas. Se em The hidden musicians configuravam-se redes convergentes ligadas a práticas musicais, várias delas etnografadas pela autora, em Tales of the city as narrativas pessoais apontam para múltiplas direções - e curiosamente a música praticamente desaparece do cenário analítico, ao menos para os agentes pesquisados. ${ }^{2 I}$ Tais narrativas pessoais, através de um "eu" que enfatiza sua trajetória de vida, pautam-se sobretudo por recortes temporais balizados por distintas gerações, por relações de aliança, parentesco e amizade e por uma série de continuidades e rupturas (Finnegan, 2004:73-8I); há também claras convenções culturais de forma, estrutura, compreensão ou modos de contar (Finnegan, 2004: I 23); referências das narrativas acadêmicas ou dos planejadores ganham aqui novas sínteses, evidentemente menos abstratas, ao mesmo tempo que revelam como Milton Keynes pôde aos poucos se transformar para muitos num lar ou lugar, sobretudo porque muitas trajetórias dizem respeito à vinda de um outro contexto, suscitando arranjos vivenciais, no plano familiar ou no conjunto de relações com os habitantes locais, ligados ao que Finnegan denomina mitologia urbana e seus temas recorrentes (Finnegan, 2004: I55-I64; ver caps. 3 e 4).

Em síntese, embora os relatos acadêmicos sobre a cidade moderna, as histórias da própria cidade de Milton Keynes e as narrativas pessoais dos moradores da região de Fishermead tenham suas particularidades, pautar-se-iam todas pela busca de coerência e persuasão, por um senso de ordenação moral, por referências (ainda que variáveis) sobre o papel da comunidade, por oposições entre campo e a cidade e pela ênfase na continuidade e nas experiências individuais ativas (Finnegan, 2004: I65-I80). ${ }^{22}$

\section{UM DIA EM MILTON KEYNES:}

\section{CAMINHO PERCORRIDO E BREVES CONCLUSÕES}

Enquanto lia os trabalhos de Finnegan, busquei contatar pessoas que já tivessem vivido em Milton Keynes, meses antes da minha ida à Inglaterra. ${ }^{23} \mathrm{Um}$ historiador conhecido de Lisboa contou-me por e-mail sobre seu doutorado na Open University, tendo morado, numa primeira fase, próximo à universidade, mas longe da área central, que ficava a zomin de bicicleta, numa cidade, segundo ele, muito dependente do automóvel; após uma permanência em Lisboa para coleta de dados, decidiu na volta morar em Londres, basicamente porque "precisava ver gente"; mesmo na universidade poucos professores moravam em Milton Keynes, preferindo Cambridge ou Oxford; apesar de tudo, ele guardou bons amigos ali (mais do que em Londres); mas até hoje, quando 
conta a ingleses que viveu em Milton Keynes, desperta em geral um sorriso dos mesmos.

Minha ideia original era visitar a professora Ruth Finnegan em Milton Keynes, para realizar uma entrevista e ao mesmo tempo conhecer algo da cidade. Ela foi muito gentil desde o início de nossas trocas de e-mails, mas pouco antes de minha ida à Inglaterra, infelizmente adoeceu e não pôde receber-me. Já em Londres, cheguei a perguntar se ela sugeria algo para conhecer de Milton Keynes que se relacionasse a seus livros, e ela indicou alguns locais com práticas musicais, embora pudesse ser algo difícil de ser acessado em apenas um dia de visita, além de estarmos então em agosto, em que aulas e concertos em geral estavam suspensos; uma possibilidade seria assistir a alguma missa dominical; ela chegou a mencionar o Stables, um importante auditório local ligado à música, embora isto implicasse um agendamento prévio; finalmente, contou que Milton Keynes ocupa uma área extensa, e que embora haja linhas de ônibus adequadas aos moradores, sugeriu que eu usasse uma rede local de táxis para minhas locomoções.

Em Londres, a menção à minha intenção de conhecer Milton Keynes também suscitava algo jocoso por parte de alguns ingleses, como "o que você vai fazer num lugar com pessoas tão 'quadradas' (square)"? ${ }^{24}$ De toda forma, uma conjunção de atitudes generosas possibilitaram que eu visitasse o local na companhia de Robert Sansome, arquiteto de uma firma com vários projetos na cidade, sua atual companheira Maria, designer de interiores (ambos moram em Bedford, perto dali) e Eugene Fisk, artista plástico que teve um estágio de residência em Milton Keynes em I980, a partir do qual produziu dois livros: Milton Keynes: a personal view (I98I) e People in their place: Milton Keynes (I985), com escritos e desenhos, e que só então retornava ao local, 33 anos depois (hoje mora no País de Gales).

Visitamos diversos lugares afastados entre si na escala do andar, cuja locomoção era dependente do automóvel, em rotas que se alternavam entre ruas residenciais locais e autopistas, ladeadas por paisagens onde predominava um cenário bastante próximo, digamos, de uma cidade-jardim, ou de fronteiras geográficas difusas entre campo e cidade. ${ }^{25} \mathrm{~A}$ maior aproximação possível da esfera musical foi a visita ao já citado Stables, em Wavendon, um auditório de apresentações musicais, onde fomos recebidos por Peter Hall, ${ }^{26}$ um dos arquitetos responsáveis pelo projeto; apesar da sofisticação acústica e de todas as qualidades técnicas apresentadas, era difícil relacionar tal lugar ao estudo de Finnegan, voltado principalmente aos "músicos ocultos", não inseridos no que parece ser, ali, um local ligado a um circuito musical claramente profissional e comercial.

Isto nos leva a um enfoque mais detido das impressões de Eugene Fisk em seu retorno à cidade após mais de trinta anos. Vale, antes, comentar sinteticamente que seus dois livros (I98I e I985, lidos a posteriori) compõem uma 
visão de certo modo otimista e mesmo esperançosa sobre a cidade no início da década de I980: na época ele percorria a região principalmente a pé ou de bicicleta, com um olhar atento à paisagem, reconstituindo basicamente, através de desenhos e escritos, a topografia local, sua vegetação e seus vestígios históricos, que de certa forma tenderiam a se manter mesmo com o crescimento urbano, dada a concepção geral de um planejamento baseado na utopia da cidade-jardim, e que a princípio acomodaria de forma equilibrada as intervenções urbanas com o mundo campestre preexistente (Fisk, I98I, s/p). A publicação posterior, que aborda "as pessoas em seus lugares" (Fisk, I985), traça um painel bastante heterogêneo: ${ }^{28}$ homens mais idosos e com cargos proeminentes (alguns envolvidos diretamente com o planejamento urbano local), mulheres com distintas inserções locais (várias delas com significativo capital cultural e envolvidas em atividades profissionais ou comunitárias), imigrantes europeus ou asiáticos, agentes diretamente responsáveis pelas intervenções urbanas, fazendeiros, comerciantes, arquitetos(as), professores(as), integrantes de associações locais, uma budista, um policial, um sindicalista, um casal de ex-hippies que habitava um ônibus. É difícil traçar, a princípio, alguma tipologia da relação desses agentes com o local, já que remetem a trajetórias e motivações bastante distintas, embora se trate de um quadro que de certa forma questionaria certos estereótipos vinculados a respeito dessa cidade.

Voltemos então à visita, no sentido da conclusão deste artigo: nossa primeira parada foi numa pequena igreja do povoado de Willen, cuja reconstrução data de século XVII, ${ }^{29}$ quando então Eugene me perguntou por que me interessara por Milton Keynes, qual era meu trabalho, além de indagações sobre o Brasil e até sobre minhas crenças religiosas (já que conversávamos no interior da capela); no Stables, ele brincou sobre a possível existência de um fantasma da ópera, enquanto visitávamos seus interiores; à tarde, enquanto caminhávamos pela área mais central de Milton Keynes, com várias construções e intervenções urbanas que ele não conhecia, seus comentários sobre o local tornaram-se mais melancólicos, como se ali houvesse "uma energia criativa que tinha se perdido", ou como se fosse algo "belo, mas sem nada em seu interior"; nosso passeio se encerrou num shopping center de mais de $\mathrm{Ikm}$ de extensão, onde se observa maior afluência de pessoas; naquele momento, Robert criticava, por exemplo, uma antiga praça com uma fonte que se transformara numa área comercial ou um caminho viário que fora interrompido pela construção de um grande edifício; Eugene estava, ao final, mais introspectivo, embora ao olhar para árvores no interior do shopping, perguntasse-nos o quão alto elas poderiam crescer...

Como já dito, tal ida a Milton Keynes permitiria uma impressão muito inicial, sem que pudesse constituir evidentemente uma etnografia. Mas a reconstituição de todo o caminho anterior e posterior à visita suscita interrogações. Talvez um estudo originado do campo da antropologia da cidade 
tomasse Milton Keynes desde o princípio como um contexto peculiar por ter sido resultante de um planejamento integral cuja concretização sempre levanta indagações cruciais, até quanto a ser considerada uma cidade. ${ }^{30}$ De toda forma, o estudo de Finnegan (2004) a respeito propõe uma aproximação entre narrativas - por exemplo, dos estudiosos e dos habitantes locais - que em geral tendem a ser separadas em termos de investigação, já que marcadas a priori por princípios ou lógicas distintas. Também é possível dizer que a abordagem de Finnegan sobre as práticas musicais (2007) inova porque não ficou atrelada às questões que em geral decorrem de interrogações centradas na questão das cidades planejadas e que definiriam um campo de abordagens específico. Todavia, é inquietante que um livro que aborda de forma detalhada uma série densa de relações de sociabilidade seja seguido por outro sobre o mesmo contexto em que as práticas musicais quase desaparecem, substituídas por um plano de falas e representações com certa autonomia, e que constituem um outro panorama local. Talvez aqui seus enfoques prioritários, anteriores e posteriores, sobre práticas musicais ou narrativas em contextos etnográficos não ocidentais tenham de certa forma predominado, com o sacrifício de uma relação mais orgânica entre as duas obras sobre a mesma cidade, que em geral se espera encontrar em estudos mais assentados numa antropologia da cidade.

A tais indagações, entretanto, adicionam-se descobertas posteriores à visita a Milton Keynes. A primeira delas é que constatei que um dos livros já citados de Fisk (I98I) estava dentre aqueles analisados por Finnegan em Tales of the city (2004: 48 e I33) que ressaltariam positivamente a história local. ${ }^{31}$ Tempos depois, ao ler People in their place (Fisk, I985), constatei também que Maria, que participara e por vezes conduzira nosso percurso em Milton Keynes, é uma das personagens enfocadas por Eugene (na parte intitulada The interior architect, s/p), em que ficamos sabendo que, nascida em Lugano (na fronteira da Suíça com a Itália), com pouco mais de 20 anos migrou com uma amiga para a Inglaterra, tendo se estabelecido em Cranfield (entre Bedford e Milton Keynes); ela morava em I980 numa antiga Tudor House, dividida então em pequenos apartamentos, ladeada por árvores, gramados e canteiros de flores, cuja atmosfera campestre era reforçada pela presença de ovelhas, cordeiros e cavalos, onde ela enfim já se dedicava ao design de interiores.

Assim, embora eu imaginasse que o arquiteto Robert (e seu colega de profissão e amigo Peter) permitiriam naquela visita as descobertas iniciais mais relevantes acerca de Milton Keynes, não deixa de ser surpreendente ter sido possível conhecer e interagir com o artista plástico e escritor Eugene (um dos interlocutores da pesquisa de Finnegan), que por sua vez transformara a designer de interiores Maria, ali também presente, numa das personagens de seu livro.

Desta forma, ainda que a cidade seja assinalada por experiências tão distintas, vividas num espaço comum que não conduz necessariamente a inte- 


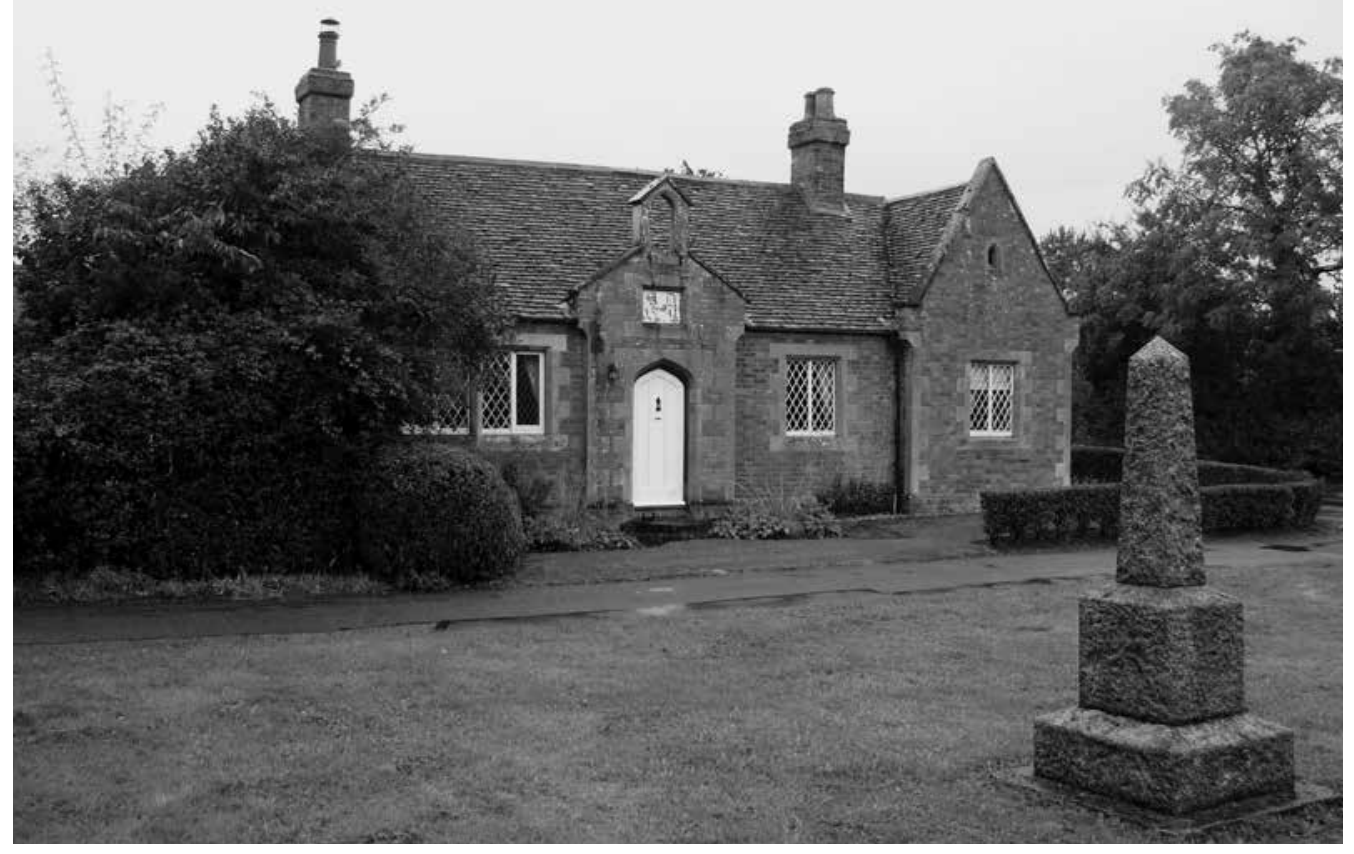

I

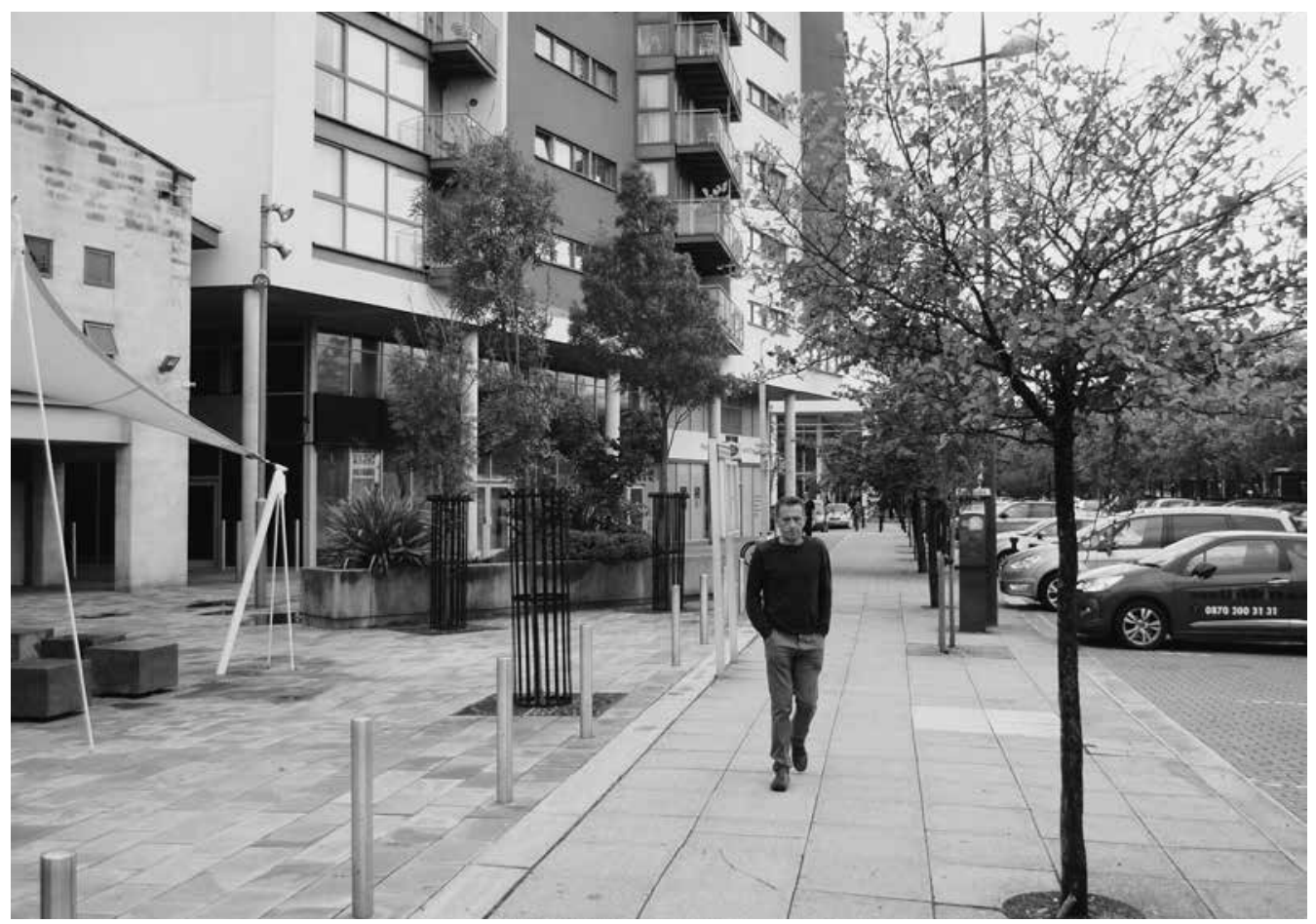


rações, não deixa de ser instigante, nos termos de Finnegan, que tenha havido uma confluência ocasional e fugaz de caminhos urbanos (urban pathways) na situação específica vivenciada num único dia, que a foto mais abaixo captou: nela aparecem Maria, personagem do livro e amiga de Eugene, que está à direita, ladeados por seu companheiro Robert e por mim, que cheguei ali por motivações de pesquisa que me levaram à leitura de obras de Ruth Finnegan (de outra forma ali também presente), que por sua vez incluiu Eugene Fisk entre os narradores que integram Tales of the city. Quem sabe tal foto, ao entrelaçar alguns personagens da experiência urbana presente e pretérita de Milton Keynes, dialogue com a intenção deste artigo de integrar as duas obras de Finnegan em seus distintos planos de análise, bem como ligar a antropologia da cidade ao conhecimento antropológico mais amplo, com base na potencialidade que as interações, quando captadas e compreendidas em seus significados, propiciam à compreensão da esfera citadina.

Recebido em 03/04/20I5 | Aprovado em 02/07/20I5

Heitor Frúgoli Jr. é professor livre-docente do Departamento de Antropologia da Universidade de São Paulo e coordenador do Grupo de Estudos de Antropologia da Cidade (USP). Foi professor titular da Cátedra de Estudos Brasileiros da Universidade de Leiden (20Io) e Directeur d'Études da École des Hautes Études en Sciences Sociales (20I3). É pesquisador do CNPq desde 2005 e conselheiro do Condephaat (Secretaria de Estado da Cultura, 2013-2016). Tem várias obras publicadas no campo da antropologia da cidade, dentre as quais Sociabilidade urbana (2007). 


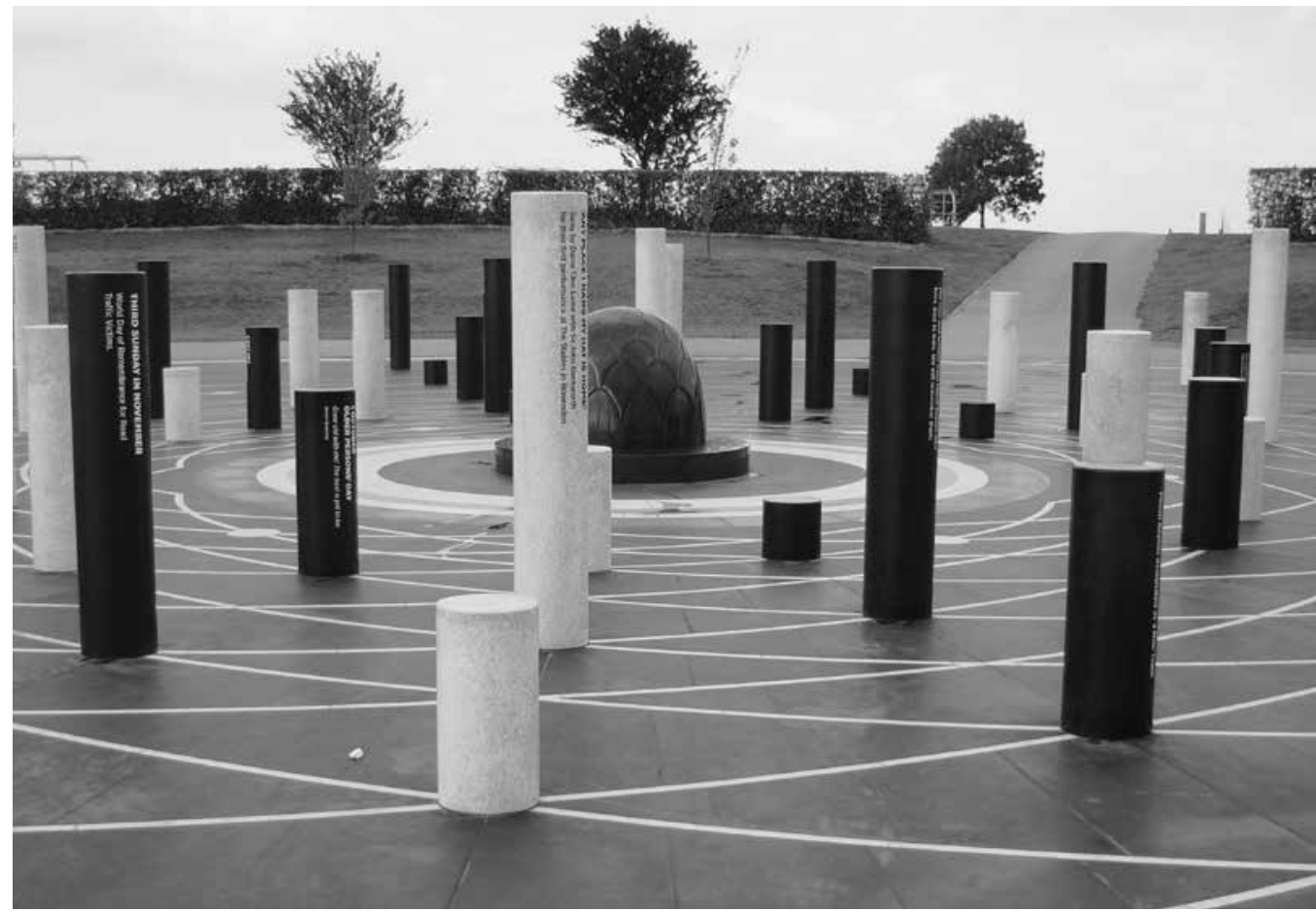

3

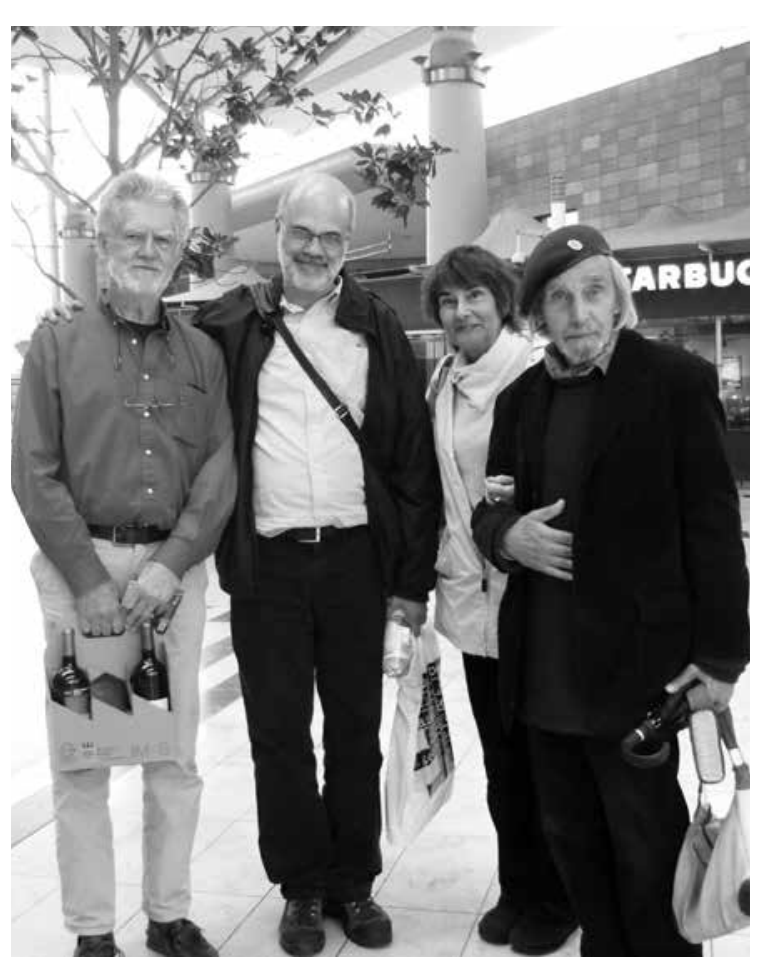

I, 2 e 3 Alguns lugares visitados: a aldeia de Willen, a área central e o Milton Keynes Rose ${ }^{27}$.

[fotos de Heitor Frúgoli Jr.]

4 Robert, Heitor, Maria e Eugene [foto de Bia Vidigal] 


\section{NOTAS}

*Agradeço pela ajuda atenciosa de Ruth Finnegan, Gonçalo Gonçalves, Jessica Sklair, Daniel Sansome, Robert Sansome, Maria, Peter Hall, Eugene Fisk, Bia Vidigal, Laura Lourenço e Delfim Martins na realização dessa pesquisa, bem como pelos retornos e comentários de Laura Cavalcanti, dos pareceristas anônimos e dos seguintes integrantes do GEAC: Alice Buratto, Eduardo Rumenig, Enrico Spaggiari, Gabriel Monteiro, Guilherme Leon, Guilhermo Aderaldo, Jessica Sklair, Julio Talhari e Maurício Alcântara.

I Sem demérito das linhas pertencentes à própria antropologia da cidade, a qual me vejo como participante.

2 Por e-mail e uma vez por telefone.

3 Dados de 20I3. Disponíveis em: <http://www.miltonkeynes.gov.uk/your-council-and-elections/statistics/population-statistics>. Acesso em I abr. 2015.

4 É claro que pesquisar a cidade também pode levar ao enfrentamento de alteridades mais radicais (personificadas muitas vezes em espaços de pobreza, privação ou violência), bem como envolver sínteses ininterruptas de distância e proximidade às vezes numa única ida a campo; mas o conhecimento acumulado sobre o próprio contexto onde se vive permite que tais impactos sejam em parte circunscritos pelo conhecimento de longo prazo da cidade onde se vive.

5 Há evidentemente, sobretudo em outras tradições de abordagens, pesquisas sobre a cidade nas quais as mesmas não são locais onde os antropólogos residem, algo talvez iniciado pela Escola de Manchester; mas neste caso, a cidade teria sido uma alteridade permanente, para quem pesquisou, sempre, em contextos distantes da própria cidade.

6 Ver detalhes em Cordeiro (2015: 23).

7 Não há como aprofundar aqui o campo abrangente que tem se configurado a respeito; sugere-se ao leitor que consulte vários números da Vibrant (ABA).

8 Sobre graus de alteridade, ver Peirano (I999).

9 Ver detalhes em entrevista de Finnegan a Macfarlane (2008) em <http://www.haujournal.org/haunet/finnegan. php $>$. Acesso em I abr. 2015. 
Io Ver entrevista a Macfarlane.

I I Ver entrevista a Macfarlane (tradução do inglês para o português de minha autoria).

I 2 Sanjek (2002 [1996]: 557) ainda afirma que antropólogos urbanos podem seguir "[...] caminhos urbanos através do trabalho de campo em pontos de parada selecionados (selected stopping points) (como fez Finnegan)". Dentre as influências nesse livro, vale ressaltar a menção de Finnegan a Howard Becker (I982) (ver entrevista a Macfarlane).

I3 A autora veio ao Brasil em 2006 para participar do evento "Palavra cantada", com destaque para o papel desempenhado pela antropóloga Elisabeth Travassos (falecida em 20I I), pesquisadora do universo musical, que resultou na publicação de coletânea com um capítulo de Finnegan (2008).

I4 Ver a elaboração a respeito no capítulo conclusivo de The hidden musicians (2007 [I989]: 327-34I).

I5 Conceito inspirado, como já dito, em Becker (I982); interessante pensar nas possíveis analogias com os "mundos sociais" de Velho (I 999).

I6 Para mais detalhes, ver Finnegan (2007: caps. 4 a Io; e 2002).

I7 Ver uma abordagem sobre agrupamentos em Herzfeld (20I4 [200I]: I72-I93).

I 8 Sua criação remonta ao plano do governo inglês de criar novas cidades após a Segunda Guerra Mundial (New Towns Act, I946), frente ao crescimento urbano e industrial de Londres e os problemas urbanos decorrentes (ver Hall, 2010 [I988]: I86).

I9 Meg Passingham, neta de Ebenezer Howard (por quem tinha carinho e admiração), nasceu e passou a infância em Hampstead (subúrbio-jardim londrino) e vivia em Milton Keynes no início dos anos 80 (Fisk, I985: s/p). Hall (2010 [1988]: I4I) inclui Milton Keynes em sua análise sobre as cidades-jardim.

20 Um tom também presente em falas de vários ingleses com quem falei sobre a cidade antes de minha visita.

2 I Com uma única exceção: ver Finnegan (2004: I03-I04).

22 Algo próximo, neste sentido, da noção de agência (Finnegan, 2004: I76). 
23 Para participar, com recursos da FAPESP, do XII Congresso Internacional da Brazilian Studies Association, ocorrido em Londres em agosto de 2014.

24 Adjetivo usado basicamente para pessoas maçantes, rigidamente convencionais ou não sintonizadas com novas ideias ou estilos.

25 Algo que fez lembrar, embora com configurações distintas, a breve pesquisa que fiz em Beuningen, na Holanda, em 200I (Frúgoli Jr., 2003).

26 Não confundir com o urbanista e geógrafo Peter Hall, já citado neste artigo (2010 [1988]), falecido nessa época.

$27 \mathrm{Um}$ espaço aberto inaugurado em 20II, projetado pelo artista Gordon Young, com pilares que simbolizam datas importantes no plano mundial, nacional, local ou pessoal, na expectativa de que ali ocorram encontros corriqueiros, eventos, celebrações, visitas de escolas etc.

28 Ainda mais porque engloba moradores dos arredores, muitos deles anteriores à própria construção de Milton Keynes.

29 Local abordado no livro (Fisk, I98I, s/p).

30 Robert chegou a comentar que, sob certo ponto de vista, Milton Keynes não seria propriamente uma cidade.

3I Outras publicações mais recentes parecem, a princípio, caminhar nessa direção, como Croft (I995 [I984]) e Lamburn, esta última com prefácio de Derek Walker, arquiteto-chefe e planejador de Milton Keynes entre I970 e I976 (Lamburn, 20 I I: 9-Io); Walker é também retratado em Fisk (I985: s/p). 


\section{REFERÊNCIAS BIBLIOGRÁFICAS}

Augé, Marc. (I994 [1992]). Não-lugares. Campinas: Papirus. Becker, Howard. (1982). Art worlds. Berkeley: University of California Press.

Cavalcanti, Maria Laura V. C. (2003). Conhecer desconhecendo: a etnografia do espiritismo e do carnaval carioca. In: Velho, Gilberto \& Kuschnir, Karina (orgs.). Pesquisas urbanas. Rio de Janeiro: Zahar, p. I I8-I38.

Cordeiro, Graça Índias. (20I5). Do próximo ao complexo: o desafio antropológico da cidade. In: Cordeiro, Graça \& Castro, Celso (orgs.). Mundos em mediação: ensaios ao encontro de Gilberto Velho. Rio de Janeiro: Ed. FGV, p. 2I-3I.

Croft, R. A. (org.). (I995 [I984]). Victorian and Edwardian Milton Keynes. Crescent Road: White Crescent Press.

DaMatta, Roberto. (I979). Carnavais, malandros e heróis. Rio de Janeiro: Zahar.

DaMatta, Roberto. (I978). O ofício de etnólogo ou como ter anthropological blues. In: Nunes, Edson de Oliveira (org.). A aventura sociológica. Rio de Janeiro: Zahar, p. 25-35.

Dumont, Louis. (I993). O individualismo. Rio de Janeiro: Rocco. Dumont, Louis. (I992 [1966]). Homo Hierarchicus. São Paulo: Edusp.

Finnegan, Ruth. (20I I). What migrates and who does it? A mini case study from Fiji. In: Toynbee, Jason \& Dueck, Byron (org.). Migrating music. Abingdon: Routledge, p. I35-I 49. Finnegan, Ruth. (2008). O que vem primeiro: o texto, a música ou a performance? In: Matos, Cláudia Neiva; Travassos, Elisabeth \& Medeiros, Fernanda Teixeira (orgs.). Palaura cantada. Rio de Janeiro: 7Letras, p. I5-43.

Finnegan, Ruth. (2007 [1989]). The hidden musicians. Middletown: Wesleyan University Press.

Finnegan, Ruth. (2004 [1998]). Tales of the city. Cambridge: Cambridge University Press.

Finnegan, Ruth. (2002). ¿Por qué estudiar la música? Reflexiones de una antropóloga desde el campo. Trans, 6, s/p. Disponível em <http://www.sibetrans.com/trans/articulo/224/por-que-estudiar-la-musica-reflexiones-de-una-antropologa-desde-el-campo>. Acesso em 5 ago. 2015. 
Finnegan, Ruth. (1988). Literacy and orality. Oxford: Blackwell. Finnegan, Ruth. (I970). Oral literature in Africa. Oxford: Clarendon Press.

Finnegan, Ruth. (I967). Limba stories and story-telling. Oxford: Clarendon Press.

Fisk, Eugene. (1985). People in their place: Milton Keynes. Milton Keynes: The People's Press.

Fisk, Eugene. (I98I). Milton Keynes: a personal view. Milton Keynes: The People's Press.

Frúgoli Jr., Heitor. (20I4). Festas populares em Lisboa: uma etnografia a partir do Bairro Alto. Etnográfica, I8/I, p. 77-98. Disponível em: <http://etnografica.revues. org/3354\#article-33>. Acesso em 5 ago. 2015.

Frúgoli Jr., Heitor. (2013a). Relações entre múltiplas redes no Bairro Alto (Lisboa). Revista Brasileira de Ciências Sociais, 28/82, p. 17-30. Disponível em: <http://www.scielo.br/pdf/ rbcsoc/v28n82/v28n82ao2.pdf>. Acesso em 5 ago. 2015.

Frúgoli Jr., Heitor. (2013b). Variations sur un quartier du centre de São Paulo. Brésil(s), 3, p. 49-67. Disponível em: <http://bresils.revues.org/4I4>. Acesso em 5 ago. 20 I5.

Frúgoli Jr., Heitor. (2003). A dissolução e a reinvenção do sentido de comunidade em Beuningen, Holanda. Revista Brasileira de Ciências Sociais, I8/52, p. I07-I24. Disponível em: <http://www.scielo.br/pdf/rbcsoc/vi8n52/i8068.pdf>. Acesso em 5 ago. 2015.

Hall, Peter. (2010 [1988]). Cities of tomorrow. (3a. ed.). Malden/Oxford/Victoria: Blackwell Publishing.

Hannerz, Ulf. (I980). Exploring the city. Nova York: Columbia University Press.

Herzfeld, Michael. (20I4 [200I]). Antropologia: prática teórica na cultura e na sociedade. Petrópolis: Vozes.

Howard, Ebenezer. (I996 [1902]). Cidades-jardins de amanhã. São Paulo: Hucitec]

Lamburn, Victoria JK. (20I I). Impression Milton Keynes. West Sussex: VL Publishing.

Peirano, Mariza. (I999). Antropologia no Brasil (alteridade contextualizada). In: Miceli, Sérgio (org.). O que ler na ciência social brasileira (I 970-I 995). São Paulo/Brasília: Ed. Sumaré/Anpocs, p. 225-266 (vol. I). 
Sanjek, Roger. (2002 [1996]). Urban anthropology. In: Barnard, Alan \& Spencer, Jonathan (orgs.). Encyclopedia of social and cultural anthropology. Londres/Nova York: Routledge, p. 555-558.

Velho, Gilberto. (1999). Os mundos de Copacabana. In: Velho, Gilberto (org.). Antropologia urbana: cultura e sociedade no Brasil e em Portugal. Rio de Janeiro: Zahar, p. I I-23.

Velho, Gilberto. (I995). Introdução: o próximo e o distante. In: Velho, Gilberto (org.). Quatro viagens. Rio de Janeiro: Museu Nacional, p. I-9 (Comunicações do PPGAS, 6).

Velho, Gilberto. (I978). Observando o familiar. In: Nunes, Edson de Oliveira (org.). A aventura sociológica. Rio de Janeiro: Zahar, p. 36-46. 
A CIDADE SOB ENFOQUE ANTROPOLÓGICO: AS OBRAS DE RUTH FINNEGAN SOBRE MILTON KEYNES

Resumo

O artigo se insere num projeto em andamento de análise de obras de antropólogos cujas abordagens remetem à cidade, embora não se situem explicitamente no campo da antropologia urbana. Enfocam-se os livros The hidden musicians (2007 [1989]) e Tales of the city (2004 [1998]) da antropóloga britânica Ruth Finnegan, ambos dedicados à cidade inglesa de Milton Keynes (com 255 mil habitantes, a $70 \mathrm{~km}$ de Londres). Ao final é narrada uma breve visita ao local, assinalada por uma confluência de interações que propiciaram um avanço no estudo pretendido, principalmente quanto à busca de relações contextuais entre as duas obras em questão.

\section{AN ANTHROPOLOGICAL LOOK AT THE CITY: RUTH FINNEGAN'S STUDIES OF MILTON KEYNES}

Abstract

This article is part of a work in progress about anthropological works that focus on cities, although not explicitly classified in the field of Urban Anthropology. Two books of the British anthropologist Ruth Finnegan - The hidden musicians (2007 [1989]) and Tales of the City (2004 [1998]) Keynes (with 255,000 inhabitants and 70km from London). The final part of the article presents a brief visit to the city that illuminates certain contextual relationships between the two books through a confluence of interactions that allowed a step forward in the intended study.
Palavras-Chave

Cidade;

Práticas musicais;

Mundos plurais;

Caminhos urbanos;

Narrativas urbanas.
Keywords

City;

Musical practices;

Plural worlds;

Urban pathways;

Urban tales. 